\title{
Establishment of dominance in domestic Norway rats: Effects of the degree of captivity and social experience
}

\author{
NELSON ADAMS \\ State University of New York, Albany, New York
}

\begin{abstract}
The effect of the level of captivity and prior social experience on the establishment of dominance was examined in 16 colonies of albino rats. Males were assigned to one of four treatment groups: aggressive experience, defeat experience, exposure to electric shock, and controls. Following treatment, colonies of four males were established for 12 days in one of three different captive setings: a large outdoor pen, an indoor pen, or laboratory group cages. Effects of treatment were minimal; however, the degree of captivity significantly affected the display of aggression and the establishment of dominance relationships. In the two pen settings, attacks were more frequent and dominance relationships were established in six of eight colonies. Attacks in the laboratory cages occurred almost exclusively during the first 2 days, and no dominance relationships were established in any of eight laboratory cage colonies.
\end{abstract}

In many species, placement of unfamiliar males together often results in fighting (Marler, 1976). Many studies have demonstrated that prior agonistic experience may affect the outcome of fights among unfamiliar rodents (Blanchard, Takahashi, \& Blanchard, 1977; Corrigan \& Flannelly, 1979; Ginsburg \& Allee, 1942; Scott, 1966; Seward, 1945; van de Poll, Smeets, van Oyen, \& van der Zwan, 1982). However, these studies have often observed only initial confrontations between males tested in laboratory cages. The understanding of dominance relationships requires extended observations of animals that have become familiar with one another (Bernstein, 1981).

A second factor influencing agonistic behavior and social dominance in rats is the degree of captivity under which a colony is housed (Boice, 1981). Adams and Boice (1983) observed unequivocal dominance relationships based upon threats, attacks, and submission in a developing colony of albino rats living in a large outdoor pen. This finding was replicated and extended to a colony living in an indoor enclosure; however, colonies living in laboratory cages were not found to establish dominance relationships across a 6-month period (Adams \& Boice, 1984).

The purpose of the present study was to observe the establishment of dominance among unfamiliar males over a period of several days in one of the above-mentioned

This paper is based upon part of the author's dissertation, which was submitted to the State University of New York at Albany in partial fulfillment of the requirements for a $\mathrm{PhD}$ degree. I would like to thank C. J. Betteridge for help on the observations, and the members of my dissertation committee for helpful comments on the research. I especially thank Robert Boice for his advice throughout the research. Requests for reprints should be sent to the author, who is now at the Department of Psychology, Winston-Salem State University, Winston-Salem. NC 27110. settings: outdoor pen, indoor pen, or large laboratory cages. It was predicted that dominance relationships would be more evident in the less captive (pen) settings. A second aspect of the study was the assessment of the role of differential agonistic experience and the effect of exposure to shock on the establishment of dominance in the different environments. Aggressive experience was expected to enhance subsequent offensive behavior, and exposure to defeat or shock was expected to decrease subsequent attack and to increase defensive behavior (Flannelly, Hiraoka, \& Flannelly, 1982; Williams, 1982).

\section{METHOD}

\section{Subjects}

All rats were Sprague-Dawley albinos purchased from Taconic Farms. Sixty-four males, weighing between 400 and $500 \mathrm{~g}$, served as experimental subjects. Males were approximately 130 days of age upon arrival; they were selected at this age because earlier findings had indicated that dominance is not established until about 140 days of age (Adams \& Boice, 1983, 1984). Two males, weighing 500-600 g, served as aggressive residents, and 32 males, weighing $350-450 \mathrm{~g}$, were used as intruders. In addition, 16 females were used when the colonies were formed. One experimental male died just prior to formation of the colonies.

\section{Housing}

Males were housed individually during the treatment phase in $35 \times 70 \times 30 \mathrm{~cm}$ glass cages with wire-mesh tops and beta chip bedding. After colony formation, the males were observed in either an outdoor enclosure measuring $6.5 \times 13 \mathrm{~m}$ (see Boice \& Adams, 1980), an indoor enclosure with glass sides and a mesh top (1.5 $\times 2.1 \times 0.9 \mathrm{~m}$ ) half filled with topsoil, or in metal-frame, glasspaneled observational cages, measuring approximately $0.3 \times 0.6$ $\times 0.3 \mathrm{~m}$ (Boice, 1971). These environments were chosen to represent differing levels of captivity. Differences in space were necessary, inasmuch as space can be considered as a component of captivity along with the availability of burrow living. The aggressive resident males were al so housed individually in the labora- 
tory observational cages; the females and intruders were housed individually in standard metal hanging cages until utilized in tests or colonies.

\section{Procedure}

Experimental treatment. Experimental males were purchased in four squads of 16. Males of each squad were assigned randomly to one of four treatment groups. Resident-experienced (RE) males were exposed to a male intruder for $30 \mathrm{~min}$ on four occasions during the 2 -week treatment period. The first two intruders were nonexperimental animals-the intruder males described in Subjects above. The third and fourth intruders for each RE male were experimental animals from the intruder-experience (IE) group described next. The second experimental group of males was exposed to four defeats as intruders (IE). Each of these males was placed into the cage of one of the nonexperimental aggressive resident males for their first two experiences; the IE males' third and fourth exposures as intruders were with the RE males described above. A third group of males was exposed to four sessions of inescapable footshock (IS). In each session, the males were confined to a small chamber and received 80 randomly scheduled 5-sec shocks of $0.9-\mathrm{mA}$ intensity. A fourth group of males served as controls (CO); these males received no social experience during the treatment phase. $\mathrm{CO}$ males were placed in unpowered shock chambers during the same period that IS males received shock. All four groups were exposed to the experimental sessions at approximately 72 -h intervals during the 2 -week period. Treatment began after the males had been individually marked and had habituated to their cages for 4 days. Food and water were continuously available during this period.

Colony formation. After the 2 -week treatment phase, colonies were established. These were composed of one male from each of the experimental groups, with none of the RE and IE males having had previous agonistic experience with one another. Two colonies were assigned to the laboratory cage setting, and one was assigned to each of the enclosures. Overall, there were eight cage colonies and four of each type of pen colony. A female was added to each colony on the 2 nd day of colony formation in order to enhance the agonistic behavior among the males (Flannelly \& Lore, 1977). Water was continuously available, and fresh food (Wayne Lab-blox) was provided each day at the beginning of observation periods.

Observations. The colonies were observed for 12 consecutive days under red-light conditions; the cage colonies were observed at $1500 \mathrm{~h}$, and the indoor colonies were observed at $1600 \mathrm{~h}$ as lights went off in those respective rooms. The outdoor colonies were observed at approximatley $2000-2100 \mathrm{~h}$ (dusk to darkness). Each colony was observed during 10 time samples, during which each of the four males was observed in series for 30-sec durations.

During the observations, the following behaviors were recorded: General activity was calculated from the percentage of time samples in which the focal rat was active outside of the burrows or nestboxes. Affiliation included social sniffing, social grooming, and other types of nonspecific social contact. Play fighting was recorded when males pinned or boxed one another with no signs of submission from the "loser" of the interaction (Symons, 1978). Threats and attacks were recorded for males that displayed the lateral threat posture, chasing, or biting-kicking attacks. Defense was recorded for males that displayed direct flight, vocalization, the upright submissive posture, or "avoidance" (unprovoked flight after contacting another male). Defeats were recorded when males were chased and/or bitten. Behavioral data were divided into three 4-day blocks so that the effects of initial confrontation could be distinguished from more long-lasting changes in social behavior.

Dominance was measured in a dyadic fashion within the context of colony interactions. That is, there were 12 possible dominance relationships that could be established among four males in a colony. A male was classified as dominant if he displayed at least one bitingkicking attack followed by four other occasions of attacks, threats, or chases that resulted in flight, submissive postures, or subsequent avoidance in another individual male. Thus, dominance was not based purely on the number of offensive behaviors, but on how the offensive behavior was distributed toward individuals in the colony. A further restriction for classifying a dominant/subordinate pair was related to the view that dominance is a relationship between familiar individuals. Accordingly, a dominant male's attacks had to be observed across two of the three 4-day blocks, and could not be restricted to just a series of interactions on 1 or 2 consecutive days.

In addition to behavioral measures, the body weights of all males were recorded before treatment, after treatment, and after the colony period. Upon sacrifice of all subjects, the adrenals, seminal vesicles, and testicles were weighed.

\section{RESULTS}

During the experimental treatment phase, all IE males were attacked severely, although they were not attacked consistently in every session. IE males received a mean of 3.3 biting attacks per experimental session. Not all RE males attacked intruders ( 4 of 15 did not), but all did display the lateral threat posture. The mean number of biting attacks delivered by RE males was 2.5 per session.

Dominance relationships were established in only 6 of the 16 colonies; in each of these 6 colonies only one male became dominant. The number of subordinates varied in these colonies: in 2 colonies, all other males were subordinate to the dominant male; in 1 colony, two males were subordinate and one was neutral; and in 3 colonies, only one male was subordinate to the dominant male. Thus, there were 6 dominant males, 11 subordinate males, and 7 neutral males from those 6 colonies (see Table 1). Serious aggression was observed in all other colonies, but attacks and submissions were not displayed in an asymmetric pattern among individuals across days.

The results of experimental treatment on the establishment of dominance is displayed in Table 1 for the 24 males described above. A chi-square test did not indicate any deviation from chance $\left[\chi^{2}(6)=4.9, p>.5\right]$ for the effect of prior agonistic or shock experience. However, it is notable that none of the IE males established dominance and that five of the six IE males were subordinate.

Figures 1 and 2 display the agonistic behavior of males across treatment groups and captive environments for three 4-day blocks. An analysis of variance found that there was no significant difference for the effects of experimental treatment on the amount of attack/threat be-

Table 1

Effects of Prior Experience on the Number of Rats Establishing Dominance Relationships

\begin{tabular}{lccc}
\hline & \multicolumn{3}{c}{ Social Status } \\
\cline { 2 - 4 } $\begin{array}{c}\text { Experimental } \\
\text { Treatment }\end{array}$ & Dominant & Subordinate & Neutral \\
\hline Resident (RE) & 2 & 2 & 2 \\
Intruder (IE) & 0 & 5 & 1 \\
Shock (IS) & 2 & 2 & 2 \\
Control (CO) & 2 & 2 & 2 \\
\hline
\end{tabular}




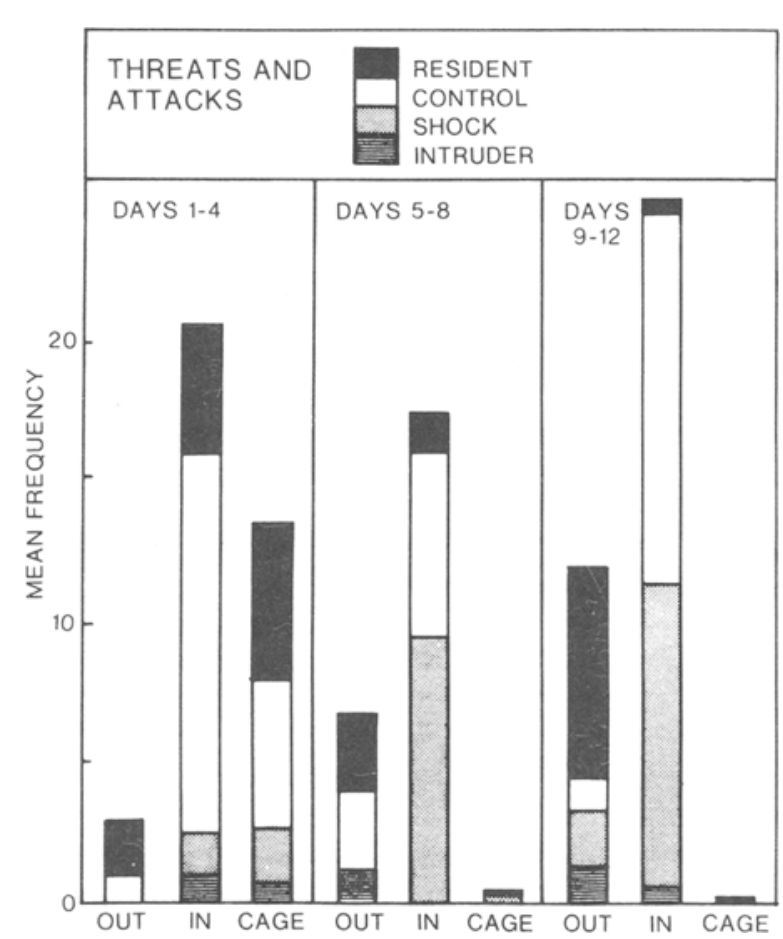

Figure 1. Mean frequency of threats and attacks for each treatment group in outdoor pen (Out), indoor pen (In), and observational cages (Cage) across 4-day blocks.

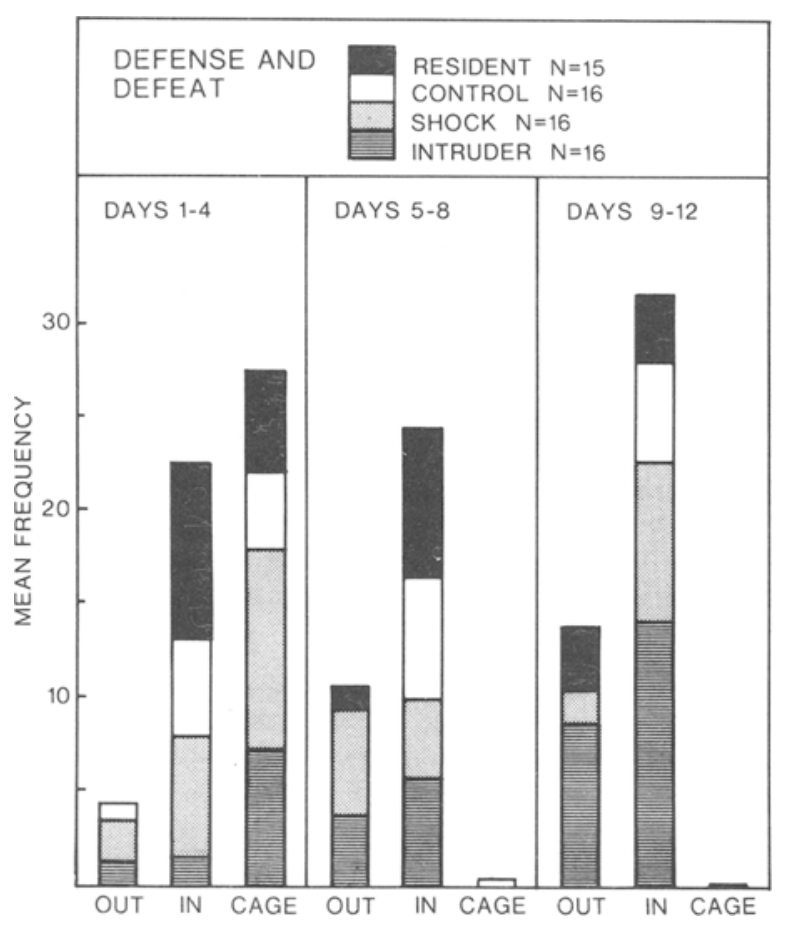

Figure 2. Mean frequency for defensive behavior and defeats for treatment group, captive setting, and 4-day blocks. havior, or for defensive/defeat behavior. Treatment did significantly affect body weight $[\mathrm{F}(3,51)=3.81, \mathrm{p}<$ $.05]$; RE males gained the most weight, and only the IS males lost weight during that period. There were no differences for organ weights across treatment groups.

The effect of the captive environment had a major influence on the establishment of dominance. Males became dominant in three of the four outdoor colonies and in three of four indoor colonies; in contrast, there were no cage colonies in which a dominance relationship was established and maintained. A chi-square test indicated that this was a significant difference $\left[\chi^{2}(2)=8.1, \mathrm{p}<.025\right]$.

The degree of captivity significantly affected the display of agonistic behavior $[\mathrm{F}(2,51)=3.5, \mathrm{p}<.05]$. It is notable that agonistic behavior was frequent in all types of colonies, yet dominance emerged in only the enclosure colonies. A significant interaction for blocks of days and degree of captivity $[F(4,102)=3.3, p<.02]$ indicated that the pattern of agonistic behavior across days in the cage colonies was different from that of rats in the outdoor and indoor colonies (see Figures 1 and 2). Minimal levels of threat, attack, and submission occurred in the second and third 4-day blocks in the cage colonies, whereas during the third block the males in the enclosure colonies displayed the most agonistic behavior.

The degree of captivity affected other social behavior such as play fighting. Frequencies of play fighting were significantly different across the colonies $[\mathrm{F}(2,51)=3.7$, $\mathrm{p}<.05]$. Each captive group differed from the other two [p $<.05$, Newman-Keuls], with cage colony males playfighting the most and outdoor males play-fighting the least (see Figure 3). There was no correspondence between the number of play fights and dominance status or number of attacks and threats for individual rats $(F<1)$.

\section{DISCUSSION}

Effects of the degree of captivity far outweighed the influence of prior shock or social experience. No significant differences in agonistic behavior could be attributed to prior social or shock experience. There did appear to be a tendency for offensive behavior to be inhibited by prior defeat experience, because no IE males became dominant and the IE group ranked highest in defensive behavior and lowest in offensive behavior. It is possible that defeat experience has more influence on subsequent behavior than does victorious social experience (Seward, 1945; van de Poll, de Jonge, van Oyen, \& van Pelt, 1982). However, no clear treatment effect may be attributable to the relatively low level of attack experience in the RE group. There was also no effect of shock on subsequent agonistic behavior. Flannelly et al. (1982) and Williams (1982) found that exposure to shock decreased subsequent aggression in mice and rats, respectively. However, Heller (1979) found increased agonistic behavior in mice that had been exposed to prior shock. Clearly, additional research is needed in order to under- 


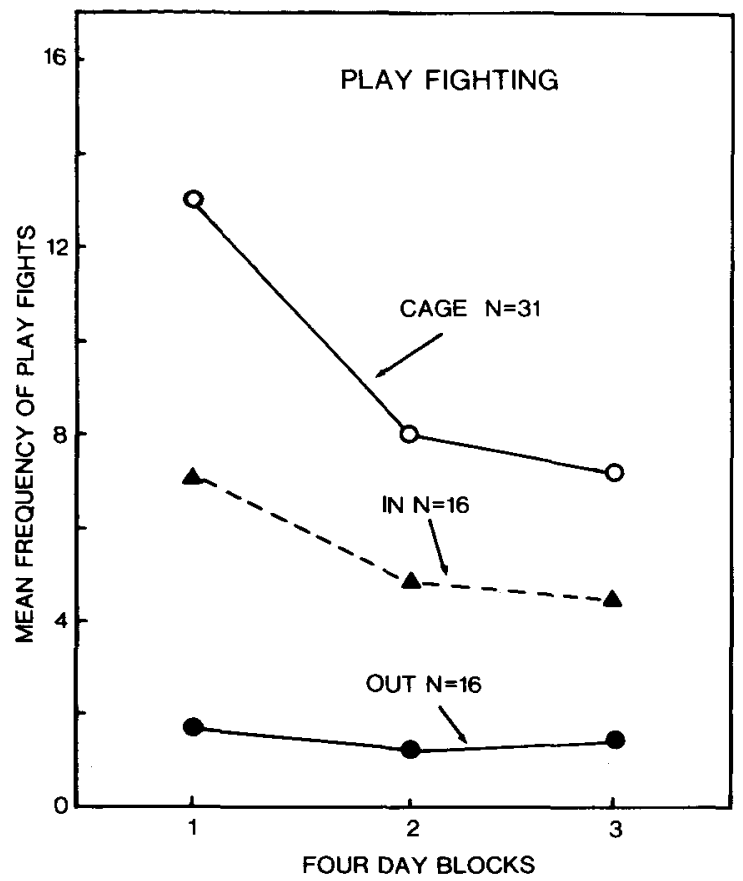

Figure 3. Mean frequency for play fighting for the three captive settings across days.

stand the effects of shock on subsequent social behavior.

The effects of the physical environment had a dramatic effect on the pattern of agonistic behavior across days and on the establishment of dominance relationships. Only in the indoor and outdoor pen colonies did asymmetric agonistic relationships emerge among colony males. Males from the cage colonies readily displayed agonistic behavior, including biting attacks, but there was no obvious influence of 1 st and 2 nd day fighting on social interactions on subsequent days. No subordinate behaviors or threats or attacks were observed in any consistent pattern after the 2 nd day of colony formation. In contrast, males in the indoor and outdoor colonies established dominance relationships over a period of days; some of the first 2 days' fighting asymmetries were reversed, and in both enclosures fighting was actually more common during the last 4-day block than during any previous block. Thus, the agonistic behavior was observed across several days in the pen colonies and did not appear to be controlled by the same factors as the cage colonies.

That is, it appears possible that under high degrees of captivity, the major factors influencing agonistic behavior among males are strangeness (Marler, 1976), novelty (Galef, 1970), and social disorganization (Scott, 1974). As familiarity increases, the amount of agonistic behavior tends to decrease; this was the pattern observed in the cage colonies. On the other hand, in the enclosure colonies, familiarity did not appear to fully inhibit agonistic behavior. It seems possible that these males were influenced less by strangeness and novelty and more by factors related to establishing dominance.
These findings are similar to the results reported for developing colonies of rats living under these same captive conditions (Adams \& Boice, 1984). In that longitudinal study, which covered a 6-month period, cage-colony males never fought among themselves but were highly aggressive toward male intruders. Males developing in the enclosures not only attacked male intruders, but established clear dominance relationships once they reached 140 days of age. Boice and Adams (1983) also found differences in these captive settings, although slight differences in age, group size, and sex ratio could have had an influence on the agonistic behavior.

Thus, it appears that the enclosure settings support social systems in which males establish dominance based upon fighting. In contrast, males in restrictive cage settings do not fight with familiar males, although they are easily induced to fight with strangers. Further research is needed to specify whether the differences in the captive environment are related to space and/or burrow living. Overall, the results suggest that the study of intermale aggression can be broadened by the observation of domestic rats in more naturalistic environments (Brain, 1981) that support the type of social interactions required for the establishment and maintenance of social dominance.

\section{REFERENCES}

Adams, N., \& Boice, R. (1983). A longitudinal study of dominance in an outdoor colony of domestic rats. Journal of Comparative Psychology, 97, 24-33.

ADAms, N., \& BoICE, R. (1984). Degrees of captivity and the development of social dominance in domestic Nonway rats (Rattus norvegicus). Manuscript submitted for publication.

Bernstein, I. S. (1981). Dominance: The baby and the bathwater. Behavioral and Brain Sciences, 4, 419-457.

Blanchard, R. J., Takahashi, L. K., \& Blanchard, D. C. (1977). The development of intruder attack in colonies of laboratory rats. Animal Learning \& Behavior, 5, 365-369.

BoICE, R. (1971). Laboratorizing the wild rat (Rattus norvegicus). Behavior Research Methods \& Instrumentation, 3, 177-182.

BoIce, R. (1981). Captivity and feralization. Psychological Bulletin, 89, 407-421.

BoIce, R., \& ADAms, N. (1980). Outdoor enclosures for feralizing rats and mice. Behavior Research Methods \& Instrumentation, 12, 577-582.

BoICE, R., \& ADAms, N. (1983). Degrees of captivity and aggressive behavior in domestic Norway rats. Bulletin of the Psychonomic Society, 21, 149-152.

Brain, P. F. (1981). The concept of dominance also has problems in studies of rodents. Behavioral and Brain Sciences, 4, 434-435.

Corrigan, J. G., \& FlanNelly, K. J. (1979). Ultrasonic vocalizations of defeated male rats. Journal of Comparative and Physiological Psychology, 93, 105-115.

Flannelly, K. J., Hiraoka, A., \& Flannelly, L. (1982). Prolonged suppressive effects of pain on territorial aggression in mice. Psychological Reports, 51, 52-54.

FLANNELLY, K. J., \& LoRE, R. (1977). The influence of females upon aggression in domesticated male rats (Rattus norvegicus). Animal Behaviour, 25, 654-659.

Galef, B. G., JR. (1970). Aggression and timidity: Responses to novelty in feral Norway rats. Journal of Comparative and Physiological Psychology, 70, 370-381.

GinsBURG, B., \& AlLEE, W. C. (1942). Some effects of conditioning on social dominance and subordination in inbred strains of mice. Physiological Zoology, 15, 485-506. 
Heller, K. E. (1979). An attempt to separate roles of corticosterone and ACTH in the control of post-shock fighting behaviour in male laboratory mice. Behavioural Processes, 4, 231-238.

MARLER, P. (1976). On animal aggression: The roles of strangeness and familiarity. American Psychologist, 31, 239-246.

Scott, J. P. (1966). Agonistic behavior of mice and rats: A review. American Zoologist, 6, 683-701.

ScotT, J. P. (1974). Agonistic behavior in primates: A comparative perspective. In R. L. Holloway (Ed.), Primate aggression, territoriality, and xenophobia. New York: Academic Press.

SEWARD, J. P. (1945). Aggressive behavior in the rat. II. An attempt to establish a dominance hierarchy. Journal of Comparative Psychology, 38, 213-224.

SYmons, D. (1978). Play and aggression. New York: Columbia University Press. van de Poll, N. E., de Jonge, F., van Oyen, H. G., \& van Pelt, J. (1982). Aggressive behaviour in rats: Effects of winning or losing on subsequent aggressive interactions. Behavioural Processes, 7 , 143-155.

van de Poll, N. E., Smeets, J., van Oyen, J. G., \& van der Zwan, S. M. (1982). Behavioral consequences of agonistic experience in rats: Sex differences and the effects of testosterone. Journal of Comparative and Physiological Psychology, 96, 893-903.

WILliams, J. L. (1982). Influence of shock controllability by dominant rats on subsequent attack and defensive behaviors toward colony intruders. Animal Learning \& Behavior, 10, 305-313.

(Manuscript received June 4, 1984; revision accepted for publication November 21, 1984.) 